\title{
Development and Characterization of Wheat Germplasm with Combined Resistance to Russian Wheat Aphid and Stem Rust (Race “Ug99”) in Kenya
}

\author{
Fredrick O. Amulaka', Joyce N. Maling'a ${ }^{2}$, Mehmet Cakir ${ }^{3}$, Richard M. S. Mulwa ${ }^{{ }^{*}}$ \\ ${ }^{1}$ Department of Crops, Horticulture and Soils, Egerton University, Egerton, Kenya; ${ }^{2}$ Kenya Agricultural Research Institute, Njoro, \\ Kenya; ${ }^{3}$ Murdoch University, Perth, Australia. \\ Email: ${ }^{*}$ rmulwa@egerton.ac.ke
}

Received February $4^{\text {th }}, 2013$; revised March $1^{\text {st }}, 2013$; accepted March $28^{\text {th }}, 2013$

Copyright (C) 2013 Fredrick O. Amulaka et al. This is an open access article distributed under the Creative Commons Attribution License, which permits unrestricted use, distribution, and reproduction in any medium, provided the original work is properly cited.

\begin{abstract}
Wheat is the second most important cereal in Kenya. However, production is severely constrained by both abiotic and biotic stresses. Of the biotic stresses a devastating pest (Russian wheat aphid (RWA)) and a serious disease (stem rust race TTKS ("Ug99")) are currently the biggest problem for wheat producers in Kenya. Severe infestations by RWA may result in yield losses of up to 90\% while "Ug99" infected fields may suffer $100 \%$ crop loss. The two pests combined are seriously affecting wheat farmers' incomes because of the heavy reliance on pesticides that increase the cost of production. This study attempted to develop and characterize wheat lines that are resistant to both RWA and "Ug99" by pyramiding two major resistance genes. Three wheat varieties: "Kwale”, a Kenyan high yielding variety but susceptible to both RWA and "Ug99"; "Cook", an Australian variety carrying stem rust resistance gene Sr36 conferring immunity to "Ug99"; and "KRWA9", a Kenyan line with resistance to RWA but of poor agronomic attributes were used. A double cross $F_{1}\left(D C F_{1}\right)$ was obtained by crossing the $F_{1}$ of "Kwale $\times$ Cook" and the $F_{1}$ of "Kwale $\times$ KRWA9". The DC $F_{1}$ population was subjected to sequential screening for both RWA and "Ug99" resistance. Surviving DC $F_{1}$ progenies were left to self pollinate to obtain the $F_{2}$ of the double cross $\left(D C F_{2}\right)$. The $D C F_{2}$ progenies were sequentially screened against RWA and "Ug99" to yield a population that was resistant to both RWA and "Ug99". Genotyping of the DC $\mathrm{F}_{2: 3}$ families were conducted to select homozygous resistant plants. Data indicated that the RWA and "Ug99" resistance genes were successfully pyramided. Though races with virulence for $S r 36$ have been reported, the gene provides immunity to race "Ug99" and can still be effectively used as a component for "Ug99" resistance breeding together with other $S r$ genes.
\end{abstract}

Keywords: Wheat Germplasm; Stem Rust; Ug99; Russian Wheat Aphid (RWA)

\section{Introduction}

Russian wheat aphid (RWA), Diuraphis noxia (Kurdjumov), is one of the most noxious pests of cereal crops in the world [1]. It is a recent pest in Kenya, first identified in 1995 [2] but quickly spread to all wheat growing areas of the country. It is known to cause yield losses of up to $90 \%$ [3]. The Russian wheat aphid feeds on wheat until the plant is mature and can often be found in developing heads. When wheat plants die in response to heavy aphid feeding, the third and forth instars develop wings and fly to other crop stands [4]. Symptoms of damage include reduced plant height, sterile heads, low kernel weight,

"Corresponding author. white, yellow or purple longitudinal streaks on the leaf and in the most severe condition, plant death [5]. At least two biotypes are known to exist in Kenya [6]; they are different from those found in South Africa and USA. Currently, all Kenyan wheat commercial varieties are susceptible to the local RWA biotypes [7] and high yield losses are experienced. Thus, there is need to develop resistant wheat germplasm to counter destruction from the local RWA biotypes.

Stem rust or black rust of wheat is caused by the fungus, Puccinia graminis Pers. F. sp. tritici. The host range of this pathogen is inconsistently reported in literature but appears to be fairly wide (up to 28 species) with its main asexual host being wheat (Triticum spp.). Other cereals and a range of grasses can also become infected 
and its distribution is global. The fungus completes its sexual cycle on the broad-leaved hosts, barberry (Berberis spp.) and Mahonia spp. Infected areas are rough to the touch. The red rust or summer spore stage appears on leaves and stems as elongate pustules (uredia) containing reddish brown spore masses. The black rust or autumn spore stage (teliospores) is similar except for color [8].

In the last three decades stem rust has not been of great concern because it has been effectively controlled through selection and breeding for introgression of rust resistance genes known as $S r$ genes [9]. But in 1999, a new virulent stem rust race known as "Ug99" was found in Uganda on wheat lines known to have the stem rust resistance gene $S r 31$, a gene for which no virulence had been reported anywhere in the world. Similar virulence was observed in 2001 in Kenya [10]. The new race ("Ug99") blocks the vascular tissues in cereal grains including wheat, oats and barley. It is highly damaging to wheat production and according to experiments conducted in affected areas it was reported to have caused yield losses of up to $71 \%$ [9]. Unlike leaf or stripe rusts that may reduce crop yields, "Ug99" infected plants may suffer up to $100 \%$ loss [11]. According to FAO, an estimated $80 \%$ of the wheat varieties currently grown in the East African region are considered susceptible to "Ug99". It is believed that the new "Ug99" strain of stem rust represents a greater risk to world wheat production. Annual losses of as much as US \$3 billion in Africa, the Middle East and south Asia alone are possible [9]. If not controlled, stem rust race "Ug99" will have a major impact on food security, especially since global wheat stocks are at a historic low.

All commercial wheat varieties in Kenya are susceptible to race "Ug99". Over 60,000 accessions were recently screened at KARI-Njoro and a few have been found to possess acceptable levels of resistance against "Ug99". Among these is an Australian cultivar "Cook" (carrying stem rust resistance gene $\mathrm{Sr} 36$ ) which confers immunity to "Ug99" [12]. Development of wheat cultivars with dual resistance to both RWA and "Ug99" is therefore a priority for wheat breeders in Kenya if challenges associated with these two biotic factors are to be overcome. This study was an attempt to pyramid RWA and "Ug99" resistance genes in wheat to explore the potential for developing lines with both pest and disease resistance.

\section{Materials and Methods}

The experiment was carried out in a green house and breeding cage at Kenya Agricultural Research Institute (KARI) at Njoro. The RWA and "Ug99" resistant materials were obtained from the breeding department of KARI-Njoro. Three varieties of wheat were used in this experiment: "Kwale", a Kenyan commercial variety known to be high yielding but susceptible to both RWA and "Ug99"; "Cook", an Australian variety carrying stem rust resistance gene $\operatorname{Sr} 36$ known to confer immunity to "Ug99" at both seedling and adult plant stages; and "KRWA9", a Kenyan line known to be resistant to RWA but with poor agronomic attributes-the resistance is conferred by a single dominant gene $[7,13,14]$.

Double cross $\mathrm{F}_{1}$ (DC $\mathrm{F}_{1}$ ) was obtained by crossing the $F_{1}$ of "Kwale $\times$ Cook" and the $F_{1}$ of "Kwale $\times$ KRWA9". The DC $F_{1}$ population generated was subjected to screening against RWA using a 1-9 visual scale of [7] to score for RWA damage. The surviving RWA resistant plants were sprayed with insecticide to kill the aphids and left for one week before screening against "Ug99".

To prepare inoculum for "Ug99" urediniospores were randomly picked from the field and placed on 20 differential set for North America [15] for "Ug99" identification. After race "Ug99" confirmation, the urediniospores were used for "Ug99" screening in the greenhouse using the 0-4 scale proposed by Stakman et al., [16] to score for damage. The surviving DC $F_{1}$ progenies were left to self pollinate to generate the $F_{2}$ of the double cross (DC $F_{2}$ ). The DC $F_{2}$ progenies were sequentially screened against RWA and "Ug99" to obtain a population that is resistant to both RWA and "Ug99". Genotyping of the DC $F_{2: 3}$ families were later done to select only homozygous resistant plants.

\section{Results and Discussion}

\subsection{RWA Damage Scores for Parents, DC $F_{1}$ and DC $F_{2}$ Populations}

Seedlings of the resistant parent "KRWA9" generally indicated a resistant reaction. All seedlings of "KRWA9" were highly to moderately resistant (classes 2, 3, 4 and 5; scales of 1-9) with a mid range score of 3.3 (Table 1). The plants developed with vigorously growing leaves, although leaf folding was observed in some plants. No leaf rolling or streaking were observed on any leaves (Figure 1(c)). Leaf rolling and streaking are major symptoms of RWA infestation in wheat. The susceptible parents, "Kwale" and "Cook" showed a susceptible reaction, with a damage score of 6, 7, 8 and 9 (Table 1). This was expected as previous studies by Maling'a [7] and Macharia [12] showed that these two varieties had no RWA resistance genes. Most of their seedlings had severe chlorotic streaking and died after 14 days of infestation (Figures 1(a) and (b)). However, four seedlings of the susceptible parent "Kwale" observed to be resistant were excluded from the study as they were thought to be escapes.

The $F_{1}$ population from "Kwale" $\times$ "KRWA9" showed 
Table 1. Range of RWA damage score of parents, $F_{1}, D C F_{1}$ and $D C F_{2}$ populations.

\begin{tabular}{|c|c|c|c|c|c|c|c|c|c|c|c|c|}
\hline \multirow{2}{*}{ Test entry } & \multirow{2}{*}{ Pop. } & \multirow{2}{*}{$\begin{array}{l}\text { No. of plants } \\
\text { tested }\end{array}$} & \multicolumn{9}{|c|}{ Number of plants with damage score } & \multirow{2}{*}{$\begin{array}{c}\text { Mean range } \\
\text { score }\end{array}$} \\
\hline & & & 1 & 2 & 3 & 4 & 5 & 6 & 7 & 8 & 9 & \\
\hline \multicolumn{13}{|l|}{ Parents } \\
\hline Kwale & $\mathrm{P}_{1}$ & 180 & 0 & 0 & 0 & 1 & 3 & 70 & 51 & 41 & 18 & 7.2 \\
\hline Cook & $\mathrm{P}_{2}$ & 155 & 0 & 0 & 0 & 0 & 0 & 42 & 71 & 20 & 22 & 7.1 \\
\hline KRWA9 & $\mathrm{P}_{3}$ & 125 & 0 & 33 & 45 & 18 & 29 & 0 & 0 & 0 & 0 & 3.3 \\
\hline \multicolumn{13}{|l|}{ Single Crosses } \\
\hline Kwale $\times$ Cook & $\mathrm{F}_{1}$ & 178 & 0 & 0 & 0 & 0 & 0 & 55 & 38 & 57 & 28 & 7.3 \\
\hline Kwale $\times$ KRWA9 & $\mathrm{F}_{1}$ & 140 & 0 & 21 & 42 & 57 & 20 & 0 & 0 & 0 & 0 & 3.5 \\
\hline \multicolumn{13}{|l|}{ Double Crosses } \\
\hline $\begin{array}{c}\text { (Kwale/Cook) } \\
\times\end{array}$ & DC $F_{1}$ & 86 & 0 & 1 & 11 & 18 & 14 & 15 & 6 & 17 & 4 & 5.5 \\
\hline (Kwale/KRWA9) & $\mathrm{DC} \mathrm{F}_{2}$ & 104 & 1 & 6 & 21 & 24 & 19 & 20 & 6 & 5 & 2 & 5.0 \\
\hline
\end{tabular}

Scale: 1-3 = Resistant; 4-5 = Moderately resistant; 6 = Moderately susceptible; 7-8 = Susceptible; 9 = Very susceptible.

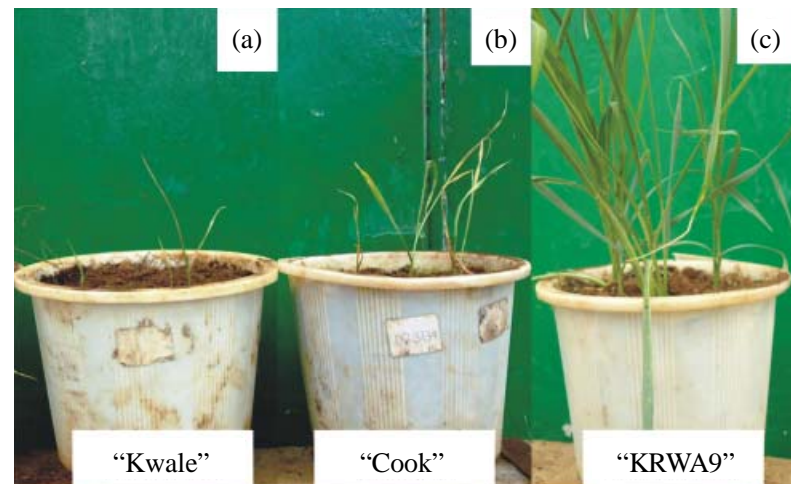

Figure 1. (a) Susceptible variety "Kwale"; (b) Variety “Cook" dying from RWA 21 days after infestation; (c) Resistant line "KRWA9” 21 days after RWA infestation.

a resistant reaction with damage scores of 2, 3, 4 and 5, recording a mid range score of 3.5 (Table 1). This is because all the $F_{1}$ progenies were heterozygous for the resistance gene. As expected, the combination of gametes carrying different alleles, one dominant from the resistant line and a recessive from the susceptible line produces a heterozygous individual; the resistant character suppresses the susceptible character [17].

On the other hand, the $F_{1}$ population from "Kwale" $\times$ "Cook" showed a susceptible reaction with damage scores of $6,7,8$ and 9 , recording a mid range score of 7.3 (Table 1). This was expected because none of the two parents has RWA resistance genes [7,13]. The DC $F_{1}$ and DC $F_{2}$ populations all indicated both susceptible and resistant reactions recording damage scores of 2-9 (Table 1) as some of seedlings were susceptible and others were resistant. This reaction followed the law of segregation- hereditary characters are determined by genes which occur in pairs and in gametogenesis the factors are segregated so that only one is transmitted by a particular gamete. The chromosome complement is restored after gamete fusion. By combining the two kinds of male and female gametes in all possible ways the relative proportions of susceptible and resistant types are obtained [17]. Some of the seedlings were homozygous dominant, some homozygous recessive and others heterozygous. The homozygous dominant and heterozygous progenies for the RWA resistance gene showed a resistant reaction while the homozygous recessive progenies were susceptible.

The mid parent value (mean range score) of $\mathrm{DC} \mathrm{F}_{1}$ was 5.5, significantly lower than the mid parent value of "KRWA9", 3.5. This is expected as only $25 \%$ of the genetic ratio was retained in the double cross. Nevertheless, the $F_{1}$ was still resistant, with DC $F_{2}$ mid parent value reported at 5.0. It is expected that $\mathrm{DC} \mathrm{F}_{2}$ would have to compensate for loss of $25 \%$ to "Cook" ( $S r)$ genes. This segregation exhibited in the DC $F_{1}$ and $D C F_{2}$ populations where there are identifiable resistant plants. The fact that they have "Kwale" characteristics in them is an indication that the RWA resistance genes can easily be introgressed into a local adapted cultivar.

\section{2. “Ug99” Infection Type on Parents, F1, DC $F_{1}$ and DC $F_{2}$ Populations}

Seedlings of the resistant parent "Cook" generally indicated resistant reactions (Figure 2(c)), recording infection types of 0 , ; and 1 (Table 2). This was expected as "Cook", a true breeding line, is known to carry the stem 


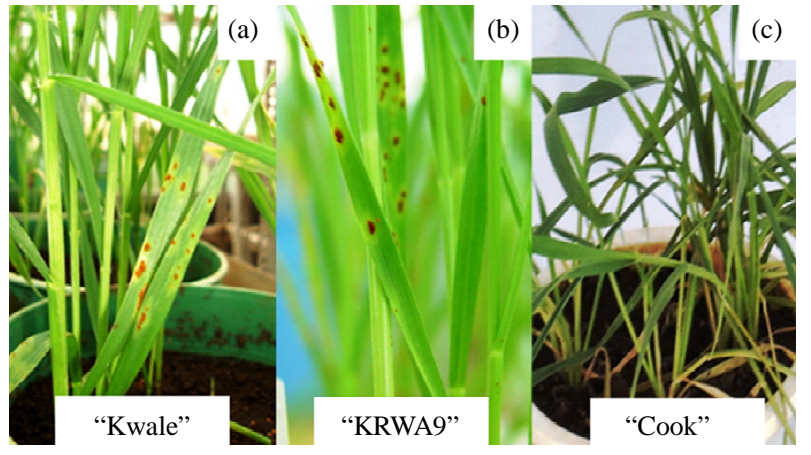

Figure 2. (a) Seedlings of susceptible parents "Kwale"; (b) "KRWA9" with medium to large sized pustules without necrotic spots 14 days post inoculation; (c) Seedlings of parent "Cook" exhibiting immunity to "Ug99" 14 days post inoculation.

rust resistance gene, $S r 36$, which confers near immunity to stem rust race "Ug99" $[12,18]$. As expected, "Ug99" susceptible parents, "Kwale" and "KRWA9", produced susceptible reactions of infection types 3 and 4 (Table 2) because the two have no resistance to stem rust race "Ug99". Most seedlings had medium to large sized pustules without necrotic spots (Figures 2(a) and (b)). A large pustule without a necrotic spot is a characteristic of high susceptibility because the plant does not exhibit the hypersensitive reaction. Hypersensitive reaction is characterized by a chlorotic or necrotic spot (fleck) where a few host cells die around the point of infection; sporulation does not occur [19]. This meant that the plants did not kill the cells around the fungal pathogen, allowing it to feed, grow and spread on other parts of the plant.

The $\mathrm{F}_{1}$ population of "Kwale" $\times$ "Cook" showed a resistant reaction, recording infection type 0 , ; and 1 (Table 2). This indicated that all the progenies were heterozygous for the resistance gene $\mathrm{Sr} 36$. The union of gametes carrying different alleles, one dominant from the resistant line and a recessive from the susceptible line produced the heterozygous individuals. In this case the resistant character seemed to suppress the susceptible character. On the other hand, the $F_{1}$ population of ("Kwale" × "KRWA9" produced a susceptible reaction with infection types of 3 and 4 (Table 2). This is because none of the two parents has "Ug99" resistance genes. All DC $F_{1}$ and DC $F_{2}$ populations produced both susceptible and resistant reactions of infection types $0, ;, 1,2,3$ and 4 (Table 2) as some of seedlings were susceptible and others were resistant. This also follows the Mendelian law of segregation. By combining the two kinds of male and female gametes in all possible ways the relative proportions of susceptible and resistant types are obtained. Some of the seedlings were homozygous dominant, homozygous recessive and others heterozygous. In this case homozygous dominant and heterozygous progenies for "Ug99" resistance gene $\operatorname{Sr} 36$ will show a resistant reaction while homozygous recessive progenies will show a susceptible reaction to stem rust race "Ug99".

\subsection{Inheritance of RWA Resistance Gene}

Seedlings of parent "Kwale" $\left(\mathrm{P}_{1}\right)$ were generally susceptible to RWA. Out of 180 plants subjected to screening against RWA, a total of 176 plants were susceptible (Table 3). This was expected as previous studies showed that "Kwale" had no RWA resistance genes [7,14]. However, four seedlings of the parent "Kwale" were found to be resistant; these were probably escapes and were excluded from the study. Similarly, seedlings of the parent "Cook" $\left(\mathrm{P}_{2}\right)$ were all susceptible to RWA (Table 3). This conforms to the findings of Macharia [12] which concluded that "Cook" had no resistance gene to RWA. Data collected on the 3rd parent "KRWA9" $\left(\mathrm{P}_{3}\right)$ generally indicated a resistant reaction to RWA (Table 3) as expected since it carries a single dominant gene that confers resistance to RWA [7,13,14].

All the $F_{1}$ progenies of "Kwale $\times$ Cook" were susceptible to RWA (Table 3). This is because neither "Kwale" nor "Cook" has genes that confer resistance to RWA. On the other hand, all the $F_{1}$ progenies of "Kwale $\times$ KRWA9" showed resistant reaction (Table 3). This is because they were all heterozygous resistant to RWA. These results confirmed that the gene in "KRWA9" was a single dominant gene as reported by Pathak et al. [13], Maling'a [7] and Kenduiwa [14].

The double cross $F_{1}$ (DC $F_{1}$ ) progenies of "Kwale/ Cook//Kwale/KRWA9" segregated in a ratio of 1:1, resistant:susceptible (Table 4), further confirming that the gene in "KRWA9" was a single dominant gene. In this case only one copy of an allele was received from the resistance gene in "KRWA9" during gamete formation, making half the population heterozygous resistant to RWA. In heterozygous individuals the only allele that is expressed is the dominant one. The double cross $\mathrm{F}_{2}$ (DC $F_{2}$ ) progenies of "Kwale/Cook//Kwale/KRWA9" showed a segregation ratio of 3:1 (resistant:susceptible) (Table 4). These results also conform to the conclusion that a single dominant gene controls the resistance conferred against RWA in the line "KRWA9".

In the double cross $\mathrm{F}_{2: 3}\left(\mathrm{DC} \mathrm{F}_{2: 3}\right)$ families, out of 48 families that were assessed against RWA only 8 families were non-segregating, 37 were still segregating and 3 were susceptible, giving a ratio of 8:37:1 (8 non-segregating:37 segregating:3 susceptible) (Table 5). This indicates that the non-segregating population was homozygous resistant to RWA while the segregating population was heterozygous resistant to RWA. Thus only a small portion of the DC $\mathrm{F}_{2: 3}$ families was homozygous 
Russian Wheat Aphid and Stem Rust (Race “Ug99”) in Kenya

Table 2. Range of “Ug99” infection type recorded on parents, $\mathrm{F}_{1}, \mathrm{DCF}_{1}$ and $\mathrm{DCF}_{2}$ populations.

\begin{tabular}{|c|c|c|c|c|c|c|c|c|}
\hline \multirow{2}{*}{ Test entry } & \multirow{2}{*}{ Population } & \multirow{2}{*}{ No. of plants tested } & \multicolumn{6}{|c|}{ Number of plants with infection type } \\
\hline & & & $\mathbf{0}$ & ; & 1 & 2 & 3 & 4 \\
\hline \multicolumn{9}{|l|}{ Parents } \\
\hline Kwale & $\mathrm{P}_{1}$ & 180 & 5 & 2 & 0 & 0 & 99 & 74 \\
\hline Cook & $\mathrm{P}_{2}$ & 155 & 94 & 59 & 2 & 0 & 0 & 0 \\
\hline KRWA9 & $\mathrm{P}_{3}$ & 125 & 0 & 0 & 0 & 0 & 56 & 69 \\
\hline \multicolumn{9}{|l|}{ Single crosses (SC) } \\
\hline Kwale $\times$ Cook & $\mathrm{F}_{1}$ & 178 & 95 & 80 & 3 & 0 & 0 & 0 \\
\hline Kwale $\times$ KRWA9 & $\mathrm{F}_{1}$ & 140 & 0 & 0 & 0 & 0 & 72 & 68 \\
\hline \multicolumn{9}{|l|}{ Double crosses (DC) } \\
\hline $\begin{array}{c}\text { (Kwale/Cook) } \\
\times\end{array}$ & DC $F_{1}$ & 44 & 11 & 6 & 3 & 0 & 16 & 8 \\
\hline (Kwale/KRWA9) & $\mathrm{DC} \mathrm{F}_{2}$ & 71 & 23 & 21 & 4 & 0 & 14 & 9 \\
\hline
\end{tabular}

Scale: 0 = immune; ; = highly resistant; 1 -2 = resistant; 3 = moderately susceptible; 4 = very susceptible.

Table 3. Seedling reaction of parents and single crosses to RWA and “Ug99”.

\begin{tabular}{|c|c|c|c|c|c|c|c|c|c|}
\hline \multirow{3}{*}{ Test entry } & \multirow{3}{*}{ Pop. } & \multirow{3}{*}{ Disease/pest } & \multirow{2}{*}{\multicolumn{3}{|c|}{ Number of plants }} & \multicolumn{2}{|c|}{ Ratio } & \multirow{3}{*}{$\chi^{2}$} & \multirow{3}{*}{ P-value } \\
\hline & & & & & & \multirow{2}{*}{$\begin{array}{c}\text { Observed } \\
\text { R:S }\end{array}$} & \multirow{2}{*}{$\begin{array}{c}\text { Expected } \\
\text { R:S }\end{array}$} & & \\
\hline & & & Total & $\mathbf{R}$ & $\mathbf{S}$ & & & & \\
\hline \multicolumn{10}{|l|}{ Parents } \\
\hline \multirow{2}{*}{ Kwale } & \multirow{2}{*}{$\mathrm{P}_{1}$} & RWA & 180 & 4 & 176 & $4: 176$ & - & - & - \\
\hline & & Ug99 & 180 & 7 & 173 & $7: 173$ & - & - & - \\
\hline \multirow{2}{*}{ Cook } & \multirow{2}{*}{$\mathrm{P}_{2}$} & RWA & 155 & 0 & 155 & $0: 155$ & - & - & - \\
\hline & & Ug99 & 155 & 155 & 0 & $155: 0$ & - & - & - \\
\hline \multirow{2}{*}{ KRWA9 } & \multirow{2}{*}{$\mathrm{P}_{3}$} & RWA & 125 & 125 & 0 & $125: 0$ & - & - & - \\
\hline & & Ug99 & 125 & 0 & 125 & $0: 125$ & - & - & - \\
\hline \multicolumn{10}{|l|}{ Single crosses } \\
\hline \multirow{2}{*}{ Kwale $\times$ Cook } & \multirow{2}{*}{$\mathrm{F}_{1}$} & RWA & 178 & 0 & 178 & $0: 178$ & $0: 1$ & 0.00 & $1.00 \mathrm{~ns}$ \\
\hline & & Ug99 & 178 & 178 & 0 & 178:0 & $1: 0$ & 0.00 & $1.00 \mathrm{~ns}$ \\
\hline \multirow{2}{*}{ Kwale $\times$ KRWA9 } & \multirow{2}{*}{$\mathrm{F}_{1}$} & RWA & 140 & 140 & 0 & $140: 0$ & $1: 0$ & 0.00 & $1.00 \mathrm{~ns}$ \\
\hline & & Ug99 & 140 & 0 & 140 & $0: 140$ & $0: 1$ & 0.00 & $1.00 \mathrm{~ns}$ \\
\hline
\end{tabular}

$\mathrm{R}=$ resistant; $\mathrm{S}=$ susceptible; $\mathrm{P}=$ probability; $\mathrm{ns}=$ No significant difference; ${ }^{\dagger}$ Significance limit of $\chi^{2}(\mathrm{P}<0.05, \mathrm{df}=1, \mathrm{CV}=3.841)$.

Table 4. Seedling reaction to RWA and "Ug99" of DC $F_{1}$ and DC $F_{2}$ populations derived from three wheat varieties.

\begin{tabular}{|c|c|c|c|c|c|c|c|c|}
\hline \multirow{3}{*}{ Test entry } & \multirow{3}{*}{ Population } & \multirow{2}{*}{\multicolumn{3}{|c|}{ Number of plants }} & \multicolumn{2}{|c|}{ Ratios } & \multirow{3}{*}{$\chi^{2}$} & \multirow{3}{*}{ P-value } \\
\hline & & & & & \multirow{2}{*}{$\begin{array}{c}\text { Observed } \\
\text { R:S } \\
\end{array}$} & \multirow{2}{*}{$\begin{array}{c}\text { Expected } \\
\mathrm{R}: \mathrm{S} \\
\end{array}$} & & \\
\hline & & Total & $\mathbf{R}$ & $\mathrm{S}$ & & & & \\
\hline RWA & \multirow{2}{*}{ DC $F_{1}$} & 86 & $44^{*}$ & 42 & $44: 42$ & 1:1 & 0.05 & $0.829 \mathrm{~ns}$ \\
\hline “Ug99” & & 44 & 20 & 24 & $20: 24$ & $1: 1$ & 0.36 & $0.546 \mathrm{~ns}$ \\
\hline RWA & \multirow{2}{*}{$\mathrm{DC} \mathrm{F}_{2}$} & 104 & $71^{*}$ & 33 & $71: 33$ & $3: 1$ & 2.38 & $0.128 \mathrm{~ns}$ \\
\hline “Ug99” & & 71 & 48 & 23 & $48: 23$ & $3: 1$ & 1.95 & $0.162 \mathrm{~ns}$ \\
\hline
\end{tabular}

$\mathrm{R}=$ resistant; $\mathrm{S}=$ susceptible; $\mathrm{P}=$ probability; $\mathrm{ns}=$ no significant difference; ${ }^{\dagger}$ Significance limit of $\chi^{2}(\mathrm{P}<0.05, \mathrm{df}=1, \mathrm{CV}=3.841)$; “"Ug99” tested on 44 and 71 RWA resistant plants of $D C F_{1}$ and $D C F_{2}$ populations respectively. 
Table 5. Seedling reaction to RWA and “Ug99” of DC $F_{2: 3}$ families derived from three wheat varieties.

\begin{tabular}{|c|c|c|c|c|c|c|c|c|c|}
\hline \multirow{3}{*}{ Test Entry } & \multirow{3}{*}{ Family } & \multicolumn{4}{|c|}{ Number of Families } & \multicolumn{2}{|c|}{ Ratios } & \multirow{3}{*}{$\chi^{2}$} & \multirow{3}{*}{ P-value } \\
\hline & & & & & & \multirow{2}{*}{$\begin{array}{c}\text { Observed } \\
\text { R:Seg:S }\end{array}$} & \multirow{2}{*}{$\begin{array}{c}\text { Expected } \\
\text { R:Seg:S }\end{array}$} & & \\
\hline & & Total & $\mathbf{R}$ & Seg. & $\mathrm{S}$ & & & & \\
\hline RWA & & 48 & $8^{*}$ & 37 & 3 & $8: 37: 3$ & $3: 12: 1$ & $64.42^{\dagger}$ & 0.001 \\
\hline "Ug99" & $\mathrm{DCF}_{2: 3}$ & 8 & 1 & 6 & 1 & $1: 6: 1$ & $1: 14: 1$ & 4.57 & $0.102 \mathrm{~ns}$ \\
\hline
\end{tabular}

$\mathrm{R}=$ Resistant; $\mathrm{S}=$ Susceptible; Seg. = Segregating plants; $\mathrm{P}=$ probability; $\mathrm{ns}=$ No significant difference; ${ }^{\dagger}$ Significance limit of $\chi^{2}(\mathrm{P}<0.05$, $\mathrm{df}=2, \mathrm{CV}=5.99)$; "“Ug99" tested on 8 RWA resistant families.

resistant; majority were heterozygous resistant.

The data collected during RWA seedling reaction of $F_{1}$, DC $F_{1}, D C F_{2}$, and DC $F_{2: 3}$ progenies drew similar conclusions; the RWA resistance gene is a single dominant gene whose inheritance can be predicted. Hence, this gene can be easily introgressed in other commercial wheat varieties possessing good agronomic attributes but which are susceptible to RWA.

\subsection{Inheritance of “Ug99” Resistance Gene Sr36}

Seedlings of parent "Kwale” $\left(\mathrm{P}_{1}\right)$ were generally susceptible to stem rust race "Ug99" with only 7 out of 180 seedlings showing an immune reaction (Table 3 ). This was expected because "Kwale" has no resistance to "Ug99" [12]. The 7 seedlings showed immune reaction probably because of disease escape and they were excluded from the study. The seedlings of parent "KRWA9” $\left(\mathrm{P}_{3}\right)$ were also susceptible to "Ug99” (Table 3) meaning that "KRWA9" has no resistance to stem rust race "Ug99". Seedlings of parent "Cook" $\left(\mathrm{P}_{2}\right)$ showed resistance reaction to "Ug99" (Table 3). This was expected because previous studies showed that the variety "Cook" carries stem rust resistance gene Sr36 which confers near immunity to "Ug99" [18]. All the $F_{1}$ progenies of "Kwale" $\times$ "Cook" showed resistant reaction to "Ug99" (Table 3). This is because the population was heterozygous resistant to "Ug99". This meant that the resistance was being conferred by a single dominant (major) gene $S r 36$. On the other hand, all the $\mathrm{F}_{1}$ progenies of "Kwale" $\times$ "KRWA" were susceptible to "Ug99" (Table 3), evidence that none of them has a resistance gene to "Ug99". The DC $F_{1}$ progenies segregated in a ratio of $1: 1$, half of the population was resistant to "Ug99" and the other half was susceptible (Table 4). This is because during gamete formation, the paired alleles separate randomly so that each gamete receives a copy of one of the two alleles. In this case half of the DC $\mathrm{F}_{1}$ progenies are heterozygous resistant to "Ug99". In heterozygosis, the only allele that is expressed is the dominant one.

The DC $\mathrm{F}_{2}$ population segregated in the ratio of $3: 1$ (3 resistant:1 susceptible) (Table 4), confirming the expression of a single dominant gene ( $\mathrm{Sr} 36)$. The data collected on $\mathrm{DC} \mathrm{F}_{2: 3}$ families showed that out of 8 families only 1 family was non-segregating to "Ug99", the other 6 were still segregating and 1 was susceptible giving a ratio of 1 non-segregating:6 segregating:1 susceptible (Table 5). This indicated that only one family was homozygous resistant to "Ug99" while the rest were heterozygous resistant.

When data of RWA and "Ug99" damage recorded on DC $F_{2}$ in Table 4 is combined, the $D C F_{2}$ population shows a segregation ratio of 9:3:3:1 (9 resistant to both RWA and "Ug99":3 resistant to RWA but susceptible to "Ug99":3 resistant to "Ug99" but susceptible to RWA:1 susceptible to both RWA and "Ug99"). This is obtained because both the RWA and "Ug99" resistance genes are single dominant genes located on different chromosomes i.e. they are not linked. Sr36 is located on chromosome 2BS [15] while it is highly suspected that the resistance gene in "KRWA9" might be located on chromosome 7D, similar to all the other $D n$ genes [13]. The fact that the two genes are not linked means that they are inherited independently hence the ratio 9:3:3:1. This is explained by the Mendelian law of independent assortment, which states that alleles of different genes assort independently of one another during gamete formation [17]. While Mendel's experiment with mixing one trait always resulted in a 3:1 ratio between dominant and recessive phenotypes, mixing two traits (dihybrid cross) showed ratios of 9:3:3:1. Independent assortment occurs during meiosis I in eukaryotic organisms, specifically metaphase I of meiosis to produce gametes with a mixture of the organism maternal and paternal chromosomes [17]. In this case the chromosomes that end up in a newly formed gamete are randomly sorted from all possible combinations of parent chromosomes. Because gametes end up with a random mix instead of a pre-defined "set" from either parent, gametes are therefore considered assorted independently. As such, the gametes can end up with any combination of "Kwale”, “Cook”, and "KRWA9” chromosomes.

In this study, the homozygous $\mathrm{DC} \mathrm{F}_{2: 3}$ population 
clearly demonstrated that it is possible to get one population that is resistant to both RWA and stem rust. This population can be advanced to early generations and selections made within preliminary and advanced yield trials for future variety release. With the constant mutations leading to evolution of new stem rust races and RWA biotypes, the strategy can be incorporated into the national wheat breeding programme to develop wheat varieties that have multiple resistance to insect pests and diseases.

\section{Acknowledgements}

We thank the Kenya Agricultural Research Institute (KARI)-Njoro for facilitation and technical support for this work. We also acknowledge Murdoch University for financial support. Additional financial support from Egerton University via the internal student research fund to FOM is highly appreciated.

\section{REFERENCES}

[1] O. V. Kovalev, T. J. Poprawski, A. V. Stekolshchikov, A. B. Vereshchagina and S. A. Gandrabur, "Diuraphis Aizenberg (Hom. Aphididae): Key Apterous Viviparous Females, and Review of Russian Literature on the Natural History of Diuraphis noxia (Kurdjumov, 1913)," Journal of Applied Entomology, Vol. 112, No. 1-5, 1991, pp. 425436. doi:10.1111/j.1439-0418.1991.tb01076.x

[2] M. Macharia, P. M. Muthangya and J. K. Wanjama, "Response to Seed-Dressing Aphicides in Commercial Varieties Russian Wheat Aphid (Diuraphis noxia) Damage in Kenya," Proceedings of the 10th Regional Wheat Workshop for Eastern, Central and Southern Africa, Pretoria University, Pretoria, 14-18 September 1999, pp. 418-421.

[3] M. Kinyua, J. Maling'a, L. Karanja and J. Wanjama, “Application of Biotechnology in Development of Bread Wheat Varieties Resistant/Tolerant to Russian Wheat Aphid (Diuraphis noxia)," In: Mukisira, et al., Proceedings of the 7th KARI Biennial Scientific Conference, Collaborative and Participatory Research for Sustainable Improved Livelihoods, 13-17 November 2000.

[4] J. Berner, "Biochemistry of Russian Wheat Aphid Resistance in Wheat: Involvement of Lipid like Products," Ph.D. Thesis, University of the Free State, Bloemfontein, 2006.

[5] V. L. Tolmay, "Genetic Variability for Russian Wheat Aphid, Diuraphis noxia Resistance in South African Wheat Genotypes," Ph.D. thesis, University of the Free State, Bloemfontein, South Africa. 2006.

[6] J. N. Maling'a, M. G. Kinyua, A. W. Kamau, J. K. Wanjama, J. O. Awalla and R. S. Pathak, "Biotypic and Genetic Variation within Tropical Populations of Russian Wheat Aphid, Diuraphis noxia (Kurdjumov) (Homoptera:
Aphididae) in Kenya,” Journal of Entomology, Vol. 4, No. 5, 2007, pp. 350-360. doi:10.3923/je.2007.350.361

[7] J. N. Maling'a, "Studies on Russian Wheat Aphid (Diuraphis noxia Kurdjumov) with Special Emphasis to Biotypes and Host Plant Resistance in Bread Wheat (Triticum aestivum L.) in Kenya,” Ph.D. Thesis, Egerton University, Njoro, 2007.

[8] J. L. Kurt, "Black Stem Rust Biology and Threat to Wheat Growers," Presentation to the Central Plant Board Meeting, US Department of Agriculture, 5-8 February 2001.

[9] CIMMYT, "Sounding the Alarm on Global Stem Rust. An Assessment of Ug99 in Kenya and Ethiopia and Potential for Impact in neighboring Regions and beyond," CIMMYT Circular, 29 May 2007.

[10] R. Wanyera, M. G. Kinyua, Y. Jin and R. P. Singh, “The Spread of Stem Rust Caused by Puccinia graminis f. sp. tritici, with Virulence on Sr31 in Wheat in Eastern Africa,” Plant Diseases, Vol. 90, No. 1, 2006, p. 113. doi:10.1094/PD-90-0113A

[11] D. Hildebrant, "Future World Wheat Crops Threatened by Ug99 Stem Rust,” Farm and Ranch Guide, 2008.

[12] K. G. Macharia, "Inheritance of Resistance Genes Sr26, Sr36 and Effectiveness of Other Major and Slow Rusiting Genes against Race 'pgt. Ug99' of Stem Rust (Puccinia graminis f. sp. tritici) in Bread Wheat," MSc. Thesis, Egerton University, Njoro, 2009.

[13] R. S. Pathak, J. N. Malinga, M. G. Kinyua, J. K. Wanjama and A. W. Kamau, "Genes for Resistance to Russian Wheat Aphid to Two New Wheat Lines," Published in 4th International Crop Science Congress, 2004.

[14] K. Kenduiwa, "Genetics of Resistance to Russian Wheat Aphid (Diuraphis noxia Mordvilko) in Bread Wheat (Triticum aestivum L.),” M.Sc. Thesis, Egerton University, Njoro, 2009.

[15] Y. Jin, L. J. Szabo, Z. A. Pretorius, R. P. Singh, R. Ward and T. Fetch Jr., "Detection of Virulence to Resistance Gene $S r 24$ within Race TTKS of Puccinia graminis f. sp. Tritici," Plant Diseases, Vol. 92, No. 6, 2008, pp. 923926. doi:10.1094/PDIS-92-6-0923

[16] E. C. Stakman, D. M. Stewart and W. Q. Loegering, "Identification of Physiological Races of Puccinia graminis var. tritici," United States Department of Agriculture, ARS E617, 1962, 53 p.

[17] D. L. Hartl and A. G. Clark, "Principles of Population Genetics," 4th Edition, Macmillan, New York, 2007.

[18] R. P. Singh, D. P. Hodson, Y. Jin, J. Huerta-Espin, M. G. Kinyua, R. Wanyera, P. Njau and R. W. Ward, "Current Status, Likely Migration and Strategies to Mitigate the Threat to Wheat,” 2006.

[19] A. P. Roelfs, "Genetic Control of Phenotypes in Wheat Stem Rust,” Annual Review of Phytopathology, Vol. 26, 1988, pp. 351-367. doi:10.1146/annurev.py.26.090188.002031 